\title{
Der Kollege, der aus der Kälte kam
}

\section{Erhard Taverna}

* Dr. med. Peter Cerny, Facharzt für Radiologie FMH, Engeriedspital, Röntgeninstitut, Riedweg 15, 3012 Bern, E-Mail: petercerny@ sonnenhof.ch

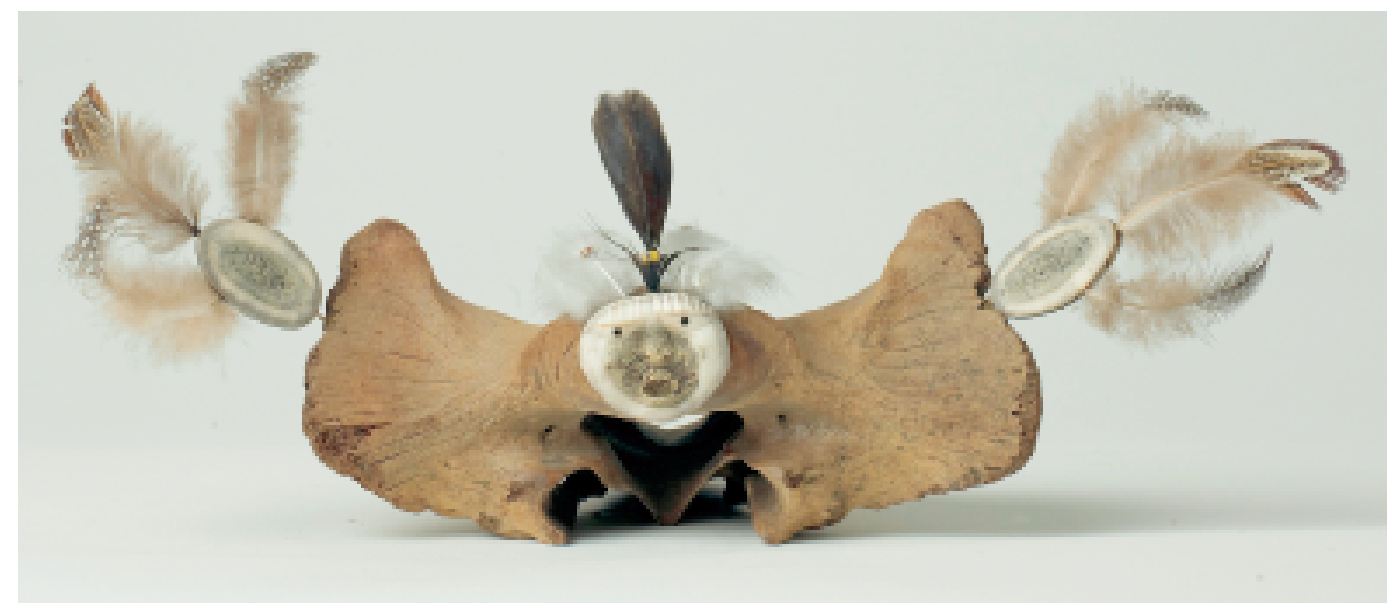

Man könnte ihn auch einen Botschafter der Arktis nennen. Einen inoffiziellen Kulturminister jener 27 verschiedenen Völker am Polarkreis, die im «arctic council» lose verbündet sind. Das geht auf ein Praktikum zurück, im Wahlstudienjahr vor über dreissig Jahren, als Peter Cerny* in einem kanadischen Indianerreservat seine spätere Ehefrau Martha kennenlernte. Aus der ersten Begegnung mit der Kunst der Einheimischen wurde eine lebenslängliche Sammlerleidenschaft, verbunden mit zahlreichen Reisen nach Alaska, Sibirien und Grönland. Die Kunst der Inuit erobert seither die Galerien von Nordamerika und wird zunehmend auch in Europa

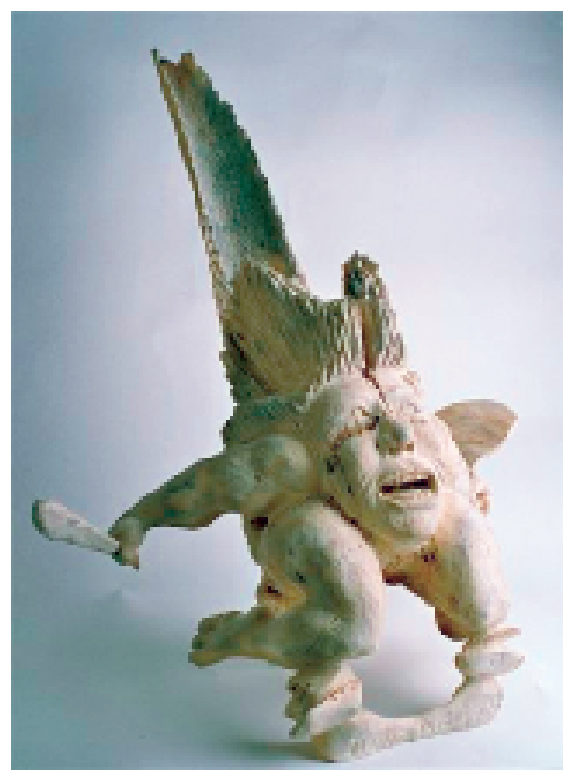

beachtet. In der Eingangshalle der UBS am Paradeplatz in Zürich ist noch bis am 1. Dezember 2006 die «Cerny Inuit Collection» zu bewundern, montags bis freitags von 8.15 bis $16.30 \mathrm{Uhr}$.

Im Mittelpunkt des runden Lichthofes glänzen die Skulpturen aus Speckstein, die Moschusochsen und Karibus, Bären und Seehunde, ein tanzendes Walross und Mutter mit Kind. Perfekte Figuren, die an europäische Meister wie Henri Moore oder Constantin Brancusi erinnern, Kostbarkeiten aus Polarwal- oder Mammutknochen, Jäger, Fischer und Schamanen, Gestalten aus der Schöpfungsgeschichte, ein Elchgeweih mit Mondkalender und ganz oben an der Spitze der Trommlergeist. Qungalukaki aus Nunavut vertreibt die bösen Geister aus der Bankhalle und hütet die Vitrinen an den Wänden. Martha und Peter Cerny erklären die zahlreichen Objekte aus Bisonknochen, Federn, Holz und Stein, aus allem, was die Polarregion ausser Schnee und Eis anbietet: Tupilaks aus Grönland, geschnitzte kleine Monster, die ähnlich dem Voodoo aus Haiti wirken, tanzende Schamanen, die sich in Tierkörper verwandeln oder zum Mond reisen, Legenden von Seehundfrauen und magischen Falken. Erstaunlich vielfältige Radierungen und Lithographien schmücken die Zwischenwände. Auch sie sind Arbeiten, die ab 1950 entstanden, als die Ureinwohner sesshaft wurden und heute beidseits der Beringstrasse in Workshops gelehrt werden.

Die Ausstellung «gemeinsame Arktis» ist aus mehreren Sammlungen hervorgegangen. Am Anfang war ein Kauf in den 90er Jahren von un- 
dokumentierten Skulpturen, Steindrucken und Batiken der Inuit. Der Radiologe aus Bern erklärt, wie er sich über die Nachforschungen zur Identität der Künstler für die Lebensweise der Völker im hohen Norden zu interessieren begann. Der Export dieser Gegenstände ist für viele Menschen der Region am Polarkreis die wichtigste Einnahmequelle. Peter Cerny möchte mit seinen Ausstellungen einen Kunstmarkt erschliessen, der mit Arbeitsplätzen für eine nachhaltige Entwicklung sorgt. Er und seine Frau organisieren Konferenzen, Vorträge und Kulturapéros für Organisationen, Firmen, Schulen und Private. In den letzten sechs Jahren ist ein weltweites Beziehungsnetz mit Künstlern, Wissenschaftlern und Politikern entstanden. Von Sponsoren wie der UBS erhofft er sich neue Kontakte über die vielen Filialen der Grossbank, Verbindungen mit Unternehmern und Staatsleuten zum Wohle der Nordvölker.

Peter Cerny erwähnt Studien zur miserablen Qualität der Eskimomuttermilch. Schadstoffe aus dem industrialisierten Süden gelangen über Meeres- und Windströme in die natürliche Nahrungskette polarer Tiere und Menschen. Das Eis zieht sich zurück, das Gewicht von Robben und Eisbären nimmt ab, das rohe Fleisch als einzige Vitaminquelle ist verseucht. Häuser, die auf Permafrostböden gebaut sind, brechen ein. Der bekannte Autor Juri Rychtëu hat sein Heimatvolk, die Tschuktschen, durch seine Romane weltweit

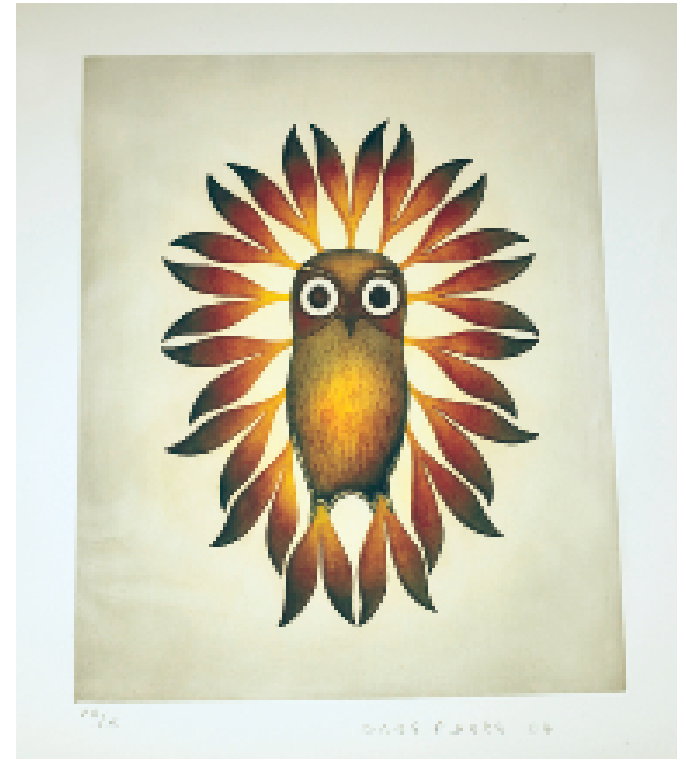

bekanntgemacht. Von ihm stammt der pessimistische Spruch: «Der Sprung über die Jahrtausende war ein Sprung ins Nichts.» Die ausgestellte Kunst versucht das Urteil abzumildern. Sie soll den Zugang zu einer Welt erleichtern, die durch unsere Lebensweise massiv bedroht ist. Martha und Peter Cerny kämpfen unermüdlich für die Zukunft einer Kultur, die unter schwierigsten Bedingungen in einem perfekten Gleichgewicht mit der Natur gelebt hat. Dass sie uns dafür die Augen öffnen, ist ihr grosses Verdienst.

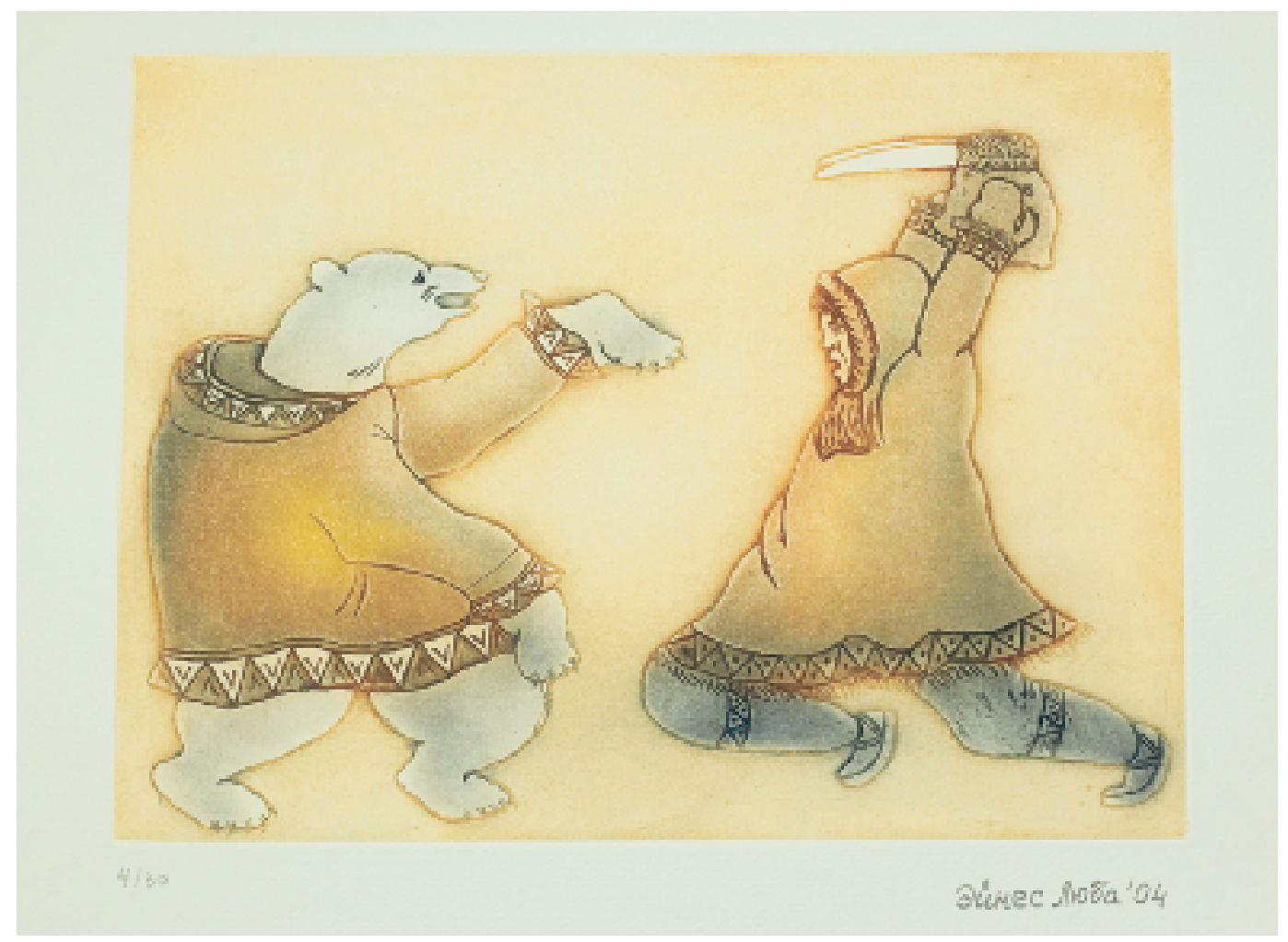

